MS09-P12

\section{Structural insights into an evolutionary intermediate of dUTPase}

Beata Vertessy ${ }^{1}$, Andras Benedek ${ }^{2}$, Ibolya Leveles

1. BME ABÉT Budapest University of Technology and Economics, Budapest, Hungary

2. BME ABÉT, Budapest, Hungary

email: vertessy@mail.bme.hu

The enzyme family of dUTPases are involved in preventive DNA repair by sanitizing the dNTP pool via hydrolyzing dUTP into dUMP and inorganic pyrophosphate (1). Metagenomic analyses revealed that dUTPases are present in samples isolated from extreme conditions with regard to pollutants, salt and thermal conditions (2). As to present, two major families of dUTPases are described. On the one hand, beta-sheeted subunits form a symmetric trimer wherein the three active sites are constituted by conserved sequence motifs from all the three subunits. On the other hand, alpha-helical subunits form a dimeris arrangement with active sites situated at the dimer interface.

We found that the within the trimeric dUTPase fold, several organisms encode the respective gene that contains three copies of the subunit in a linked arrangement such that the resulting protein product contains the three subunits in covalent linkage within one single polypeptide chain. The evolutionary pathway leading the the triplication of the ancient dUTPase gene necessarily involves a dimeric evolutionary intermediate (3).

Here we investigate if such evolutionary intermediate dUTPase enzyme may function as a catalytically active species, in constrast to the general arrangement of this enzyme family. We characterize the dimeric enzyme using enzyme kinetics and biophysical techniques. We also crystallize this evolutionary intermediate and provide structural insights into the organization of the active site.

References:

1: Vértessy BG, Tóth J. Keeping uracil out of DNA: physiological role, structure and catalytic mechanism of dUTPases. Acc Chem Res. 2009 Jan 20;42(1):97-106.

2: Szalkai B, Scheer I, Nagy K, Vértessy BG, Grolmusz V. The metagenomic telescope. PLoS One. 2014 Jul 23;9(7):e101605. 3: Benedek A, Horváth A, Hirmondó R, Ozohanics O, Békési A, Módos K, Révész Á, Vékey K, Nagy GN, Vértessy BG. Potential steps in the evolution of a fused trimeric all- $\beta$ dUTPase involve a catalytically competent fused dimeric intermediate. FEBS J. 2016 Sep;283(18):3268-86.

Keywords: folding, homology, dUTPases

\section{MS09-P13}

\section{Bacterial metal-dependent DNase with novel fold}

Jan Dohnalek ${ }^{1}$, Jan Stránský1, Vojtěch Andrle ${ }^{1}$, Mária Trundová ${ }^{1}$, Tomáš Koval ${ }^{1}$, Lars Østergaard²

1. Laboratory of Structure and function of biomolecules, Institute of Biotechnology of the Czech Academy of Sciences, Vestec, Czech Republic

2. Department of Agile Protein Screening, Novozymes A/S, Bagsvaerd, Denmark

email: dohnalek007@gmail.com

Bacillus licheniformis produces extracellular DNase NucB capable of double-strand DNA cleavage [1]. NucB is a sporulation-specific enzyme with so far unknown specificity and structure-function properties. NucB was successfully produced using bacterial expression, purified, crystallized and diffraction data were collected using synchrotron radiation and a MetalJet in-house X-ray source [2]. Systematic optimization of the key S-SAD protocol parameters was necessary to solve the phase problem [2]. The enzyme structure determined in several crystal forms uncovers a new nuclease/DNase fold. Structural analysis, bioinformatic analysis, and activity measurements for the wt and mutant forms of the enzyme led to conclusions regarding the position and composition of the active site. Detailed metal-dependence, stability and cleavage specificity profiles show the necessity of divalent ions for the activity, high temperature stability, and a time-dependent preference for the formation of single strand breaks on dsDNA substrate at sequence-specific sites.

References:

[1] van Sinderen, D., Kiewiet, R., Venema, G. (1995). Differential Expression of 2 Closely-related Deoxyribonuclease Genes, NucA and $\mathrm{NucB}$, in Bacillus subtilis. Molecular Microbiology, 15, 213-223.

[2] Stransky, J., Optimization of Macromolecular Crystallography Tools and Structural Studies of Nucleases, PhD dissertation, Czech Technical University in Prague, 2018.

Keywords: DNase, metal-dependent, X-ray structure 